\title{
Prevalence and clinical features of lumbar zygapophysial joint pain: a study in an Australian population with chronic low back pain
}

Anthony C Schwarzer, Shih-chang Wang, Nikolai Bogduk, Patrick J McNaught, Rodger Laurent

\begin{abstract}
Objectives-To determine the prevalence of pain arising from the zygapophysial joint in patients with chronic low back pain and to determine whether any clinical features could distinguish patients with and without such pain.

Methods-Sixty three patients with chronic low back pain were studied prospectively. All patients underwent a detailed history and physical examination as well as a series of intra-articular zygapophysial joint injections of $0.5 \%$ bupivacaine starting at the symptomatic level to a maximum of three levels or until the pain was abolished. They also received injections of normal saline into paraspinal muscles to act as controls.

Results-All patients proceeded with the injections. Twenty $(32 \% ; 95 \%$ confidence interval (CI) 20 to $44 \%$ ) obtained greater than $50 \%$ relief of their pain following the administration of saline. Fifty seven patients completed the study; 23 of them $(40 \% ; 95 \%$ CI 27 to $53 \%)$ failed to obtain relief following the injection of saline but obtained relief following one or more intra-articular injections of local anaesthetic. None of the historical features or clinical tests could discriminate those patients with and those without zygapophysial joint pain.

Conclusion-Pain originating from the zygapophysial joint is not uncommon, but this study failed to find any clinical predictors in patients with such pain.
\end{abstract}

(Ann Rheum Dis 1995; 54: 100-106)

Faculty of Medicine, The University of Newcastle, University Drive, Callaghan, NSW 2308, Australia A C Schwarzer

N Bogduk

Department of Radiology, Royal

North Shore Hospital, Pacific Highway, St

Leonards, NSW, 2065, Australia

$S$ Wang

Department of Rheumatology

P J McNaught

R Laurent

Correspondence to: Dr A Schwarzer.

Accepted for publication 9 September 1994

There has been considerable debate as to the role of the zygapophysial joint in chronic low back pain. Whereas some have considered this joint to be a significant source of pain ${ }^{1-16}$ others have supported opposite views. ${ }^{17-21}$

Ghormley first advanced the notion that this joint could be the source of a set of symptoms and signs in the low back and coined the term 'facet syndrome', 22 and early pathomorphological studies supported this idea. ${ }^{23}$ Anatomical studies established that the lumbar zygapophysial joints were richly innervated by nociceptive fibres which provided the anatomical substrate for pain from these joints. ${ }^{24-27}$ The landmark study by Mooney and Robertson provided important evidence for the existence of zygapophysial joint pain. ${ }^{1}$ By injecting the zygapophysial joints of normal volunteers under fluoroscopic guidance, they were able to induce both back and referred leg pain; then by injecting the same joints with local anaesthetic, they could abolish the pain. Using similar techniques, a number of authors have been able to abolish pain in $8-94 \%$ of patients suffering from low back pain. ${ }^{1-15} 172128$ Further studies demonstrated a range of pathological changes which could affect the zygapophysial joint including osteoarthrosis, ${ }^{3}{ }^{10} 29$ chondromalacia facetae, ${ }^{30}$ and even occult fractures. ${ }^{31}$

A major problem has been the inability to diagnose reliably the pain arising from the zygapophysial joint, using either clinical tests $^{10161728}$ or conventional imaging techniques. ${ }^{32}$ Two small studies reported sets of clinical signs predictive of zygapophysial joint pain, ${ }^{4} 12$ but their predictive value was not borne out in larger studies. ${ }^{16} 1728$ Plain radiographs and computed tomography are capable of showing morphological changes, but these occur as frequently in asymptomatic individuals as in symptomatic individuals. ${ }^{33-35}$

The only reliable method for making a diagnosis of zygapophysial joint pain is the injection of local anaesthetic into the putatively painful joint or around the nerves which innervate it. These diagnostic blocks are based on the precept that if a structure in the low back is the source of pain, anaesthetising that structure should abolish the pain for a period of time commensurate with the duration of action of the local anaesthetic used. If the pain is from a site other than the zygapophysial joint, such a procedure would fail to abolish the pain.

One possible confounder, however, is the

false positive response: injection of local anaesthetic may bring about relief of pain not through the pharmacological action of the drug but through some other effect beyond the immediate control of the treating physician. ${ }^{36-38}$ In order to counter this effect, the injection of an inactive substance can be used as a control. ${ }^{36}$ If the pain is not relieved by such a control injection but is relieved by the local anaesthetic, this provides strong evidence that the source of pain is indeed the putative joint.

In Australia, patients with back pain are commonly seen by rheumatologists. Of relevance to them is the prevalence of zygapophysial joint pain and how the diagnosis should 
be made. Because of the different social and medicolegal context of back pain, prevalence figures from the United Kingdom or North America do not necessarily apply to Australia. There has been one previous Australian study, but neither it nor any other study of lumbar zygapophysial joint pain used placebo controls.

The present study sought to assess the prevalence of pain arising from the lumbar zygapophysial joints and to determine if there are clinical signs that reliably discriminate patients whose pain arises from these joints from patients whose pain arises from some other source. The null hypothesis addressed was that lumbar zygapophysial joint pain is uncommon in an Australian population suffering from low back pain and cannot be predicted clinically using conventional clinical tests.

\section{Patients and methods \\ PATIENTS}

The study population consisted of patients with low back pain referred by rheumatologists at the Royal North Shore Hospital, a major Teaching Hospital in Sydney, between January 1990 and October 1991. The cause of their back pain was not evident from non-invasive diagnostic techniques. Patients were usually referred for the study if they failed to respond to conservative therapy; they were not referred if they were suspected of having anything other than a mechanical cause for their low back pain. Patients were excluded if they were under the age of 18 or over the age of 80 years, if there was a history of previous spinal surgery, if they had a neurological deficit, or if they had a malignancy, spinal infection or inflammatory spinal disorder such as ankylosing spondylitis. Patients included in the study were restricted to categories 1,2 or 3 in the classification used by the Quebec Task Force for activity related spinal disorders ${ }^{39}$ as recommended by Deyo. ${ }^{40}$ None of the patients was receiving 'worker's compensation'. The intention was to study patients with chronic low back pain who had visited a rheumatologist based at a tertiary referral centre. Although such a group represents a small subset of patients in the community with low back pain, these patients are the most difficult to treat and are the most costly to manage.

Seventy one patients were referred, of whom eight failed to proceed: two patients declined to proceed when they were told about the nature of the investigations; two patients were going to leave the country during the investigations and therefore could not proceed; one patient was diagnosed with a carcinoma of the colon and did not commence the study; and three patients experienced too little pain for them to want to proceed with any investigation. Sixty three patients were therefore admitted to the study.

The median age of the population was 59 years (interquartile range 51.0 to 68.0 ) and the female:male ratio was $3: 1$. The median duration of low back pain was seven years (interquartile range two to 20) and the median duration of the current episode of low back pain was one year (interquartile range six months to two years). The study was approved by the Ethics Committee at Royal North Shore Hospital and informed consent was obtained from all participants.

\section{ASSESSMENTS}

A detailed history was obtained from all patients and a physical examination was performed by the principal investigator. Aspects considered important were duration and severity of back pain, precipitants, exacerbating and relieving features, site of pain, sites of referred pain, associated symptoms, influence of pain on lifestyle, treatment both past and present, past history, social history and employment history. All patients were requested to document their average level of pain over the previous 24 hours and to rate their average day pain, night pain and pain on movement, using $10 \mathrm{~cm}$ visual analogue scales (VAS). The left side of the scales showed 'no pain' and the right side showed 'worst possible pain'; all measurements were in millimetres measured from the left hand margin. Patients were also requested to complete several psychometric questionnaires: the McGill-Melzack Pain Questionnaire (MPQ); $;^{41}$ the State-Trait Anxiety Inventory; ${ }^{42}$ the Beck Depression Inventory (BDI). ${ }^{43}$

The physical examination included a variety of measures that might be used in conventional medical practice in the assessment of patients with low back pain: range of lumbar spinal movement between $\mathrm{Ll}$ and $\mathrm{S} 1$, noting movements that induce pain; flexion (measured according to the modified Schober's index, using a spirit goniometer positioned $5 \mathrm{~cm}$ above the dimples of Venus, and using the extent of distraction over the distance from the level of the $\mathrm{C} 7$ spinous process to the level of the iliac crest); extension measured using a spirit goniometer; lateral flexion (measured as finger to floor distance using an erect rule, and also using a spirit goniometer held against the arm opposite to the side of lateral flexion); sites of spinal and paraspinal tenderness; extent of straight leg raising using a spirit goniometer held against the lower thigh just above the patella; combinations of rotation and extension with the patient standing and assessing whether these manoeuvres are painful; a complete rheumatological and neurological examination. In addition, blood was taken for a full blood count, erythrocyte sedimentation rate and biochemical profile.

A study was performed to assess intraobserver and interobserver agreement for the following tests: modified Schober's index; distraction of $\mathrm{C} 7$ to iliac crest distance with forward flexion; forward flexion using a spirit goniometer; extension using a spirit goniometer; lateral flexion to the right and left using finger to floor distance and spirit goniometer; extent of straight leg raising using a spirit goniometer; rotation to the right combined with extension to the left and 
rotation to the left combined with extension to the right assessing whether pain was induced. The examinations were performed by the principal investigator and a co-investigator (RL) on 10 patients. Each patient was assessed by each examiner at times 0,15 minutes, and 30 minutes.

INJECTIONS OF ZYGAPOPHYSIAL JOINTS

The criterion standard adopted for the diagnosis of zygapophysial joint pain was the response to local anaesthetic blocks of these joints. The procedure was performed using an image intensifier. Under single blind conditions, patients underwent a placebo injection followed by a series of intra-articular zygapophysial joint injections. The placebo injection was always the first injection; subsequently, on separate occasions, intraarticular injections were performed at L5-S1, L4-5, and L3-4, in that order. The injections were one week apart and the effect of each procedure was assessed for eight hours. Injections were performed sequentially until the patient became pain free or until all three levels had been injected. If a patient obtained less than $50 \%$ relief of pain at one level, that joint was not reinjected but the next joint was injected on the subsequent occasion. When it was suspected that the pain may have arisen from a level higher than L3-4, higher joints were injected; this was the case in three patients. Although patients consented to undergo placebo injections as part of the study, the order of injections was not specified and, therefore, patients were unaware of when they were receiving placebo and active injections.

Placebo injections were performed first in order to avoid any carry over effect from injection of an active agent and in order to avoid conditioning. The literature indicates that placebos become more effective when there is prior conditioning with non-placebos. ${ }^{44}$ Performing the placebo injection first avoids this risk of amplifying the placebo response rate.

Before each and every procedure, up to $5 \mathrm{ml}$ of $1 \%$ lignocaine (Xylocaine $1 \%{ }^{(\mathrm{R})}$, Astra) was infiltrated subcutaneously to provide adequate surface anaesthesia. Injections were either unilateral or bilateral, depending on whether the pain was unilateral or bilateral. Both placebo and active injections were performed with a 25 gauge, $9 \mathrm{~cm}$ spinal needle (Spinocan $^{(\mathrm{R})}$, B Braun Melsungen AG, Germany). The placebo injections consisted of $0.5 \mathrm{ml}$ of normal saline injected into muscle superficial to the zygapophysial joints in the region of the patients' pain and not deeper than $40 \mathrm{~mm}$ from the skin. Placebo injections were performed in this way in order not to interfere with the zygapophysial joint. Active injections consisted of $0.1-0.3 \mathrm{ml}$ of contrast medium (meglamine iothalamate, Conray $280^{(\mathrm{R})}$, May and Baker) to confirm intra-articular placement (figure), followed by $1.5 \mathrm{ml}$ of $0.5 \%$ bupivacaine hydrochloride (Marcain $^{(\mathrm{R})}$, Astra). Smaller volumes were used when joints would not accept the full $1.5 \mathrm{ml}$.

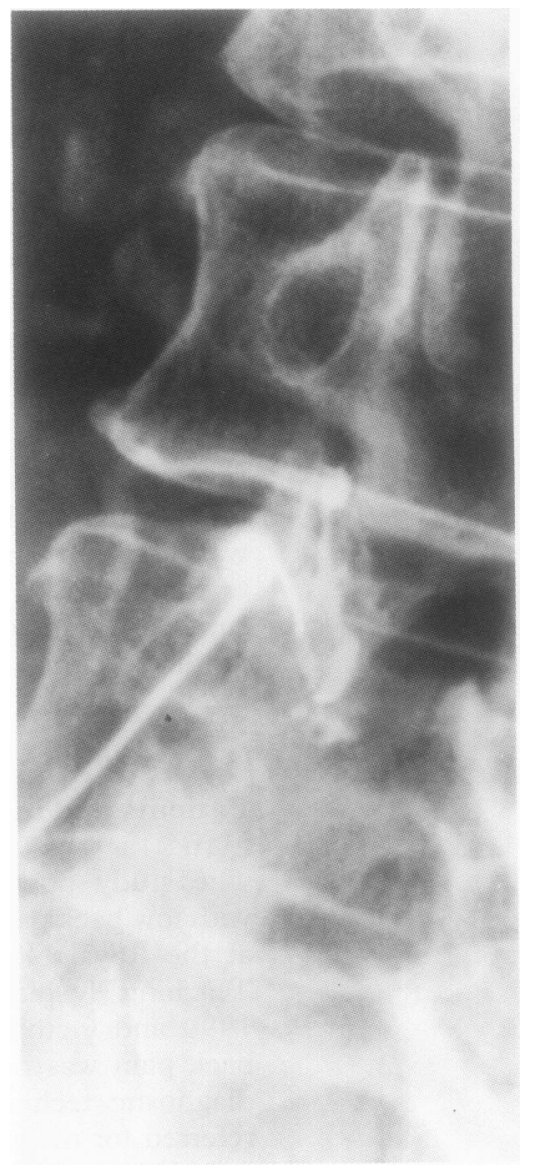

Arthrogram of a left L3-4 zygapophysial joint, demonstrating correct needle position.

ASSESSMENT OF PAIN RELIEF

Patients were assessed after both placebo and active injections using a series of $10 \mathrm{~cm}$ VASs which were completed by the patient before the procedure, 30 minutes after the procedure and then hourly for eight hours. Following each injection patients were instructed to carry on with their usual daily activities in addition to completing their VAS. Two major types of response were recognised: positive or negative. A positive response to placebo or intraarticular injections was defined as a $50 \%$ or greater reduction in pain maintained for at least three hours, consistent with the expected duration of action of bupivacaine. Amongst patients who exhibited a positive response, patients were identified in whom there was greater than $90 \%$ relief of pain or complete relief of pain for a duration of at least three hours. Patients exhibiting positive responses to the placebo injection subsequently also underwent intra-articular injections of bupivacaine if and once their usual pain returned.

The diagnosis of zygapophysial joint pain was made if the patient exhibited a positive response to zygapophysial joint injections at one or more levels but failed to respond positively to the placebo control injection.

STATISTICAL ANALYSIS

All results of history, examination and investigations were recorded on an SPSS database $^{45}$ using an IBM personal computer. 
Statistical analysis was performed using $\mathrm{BMDP}^{46}$ and the SAS statistical programme. ${ }^{47}$

For intraobserver and interobserver agreement, the kappa statistic was used for categorical variables ${ }^{48}$ and the intraclass correlation coefficient was used for continuous variables. The intraclass correlation coefficient was calculated using estimates of mean squares from a one way analysis of variance ${ }^{49}$ and $p$ values were based on the $F$ test.

The information obtained on history, physical examination and psychometric assessment was compared in patients with a diagnosis of zygapophysial joint pain and those who did not have zygapophysial joint pain. The normality of quantitative variables was assessed using the Shapiro-Wilk test. As quantitative values followed a non-parametric distribution, the Wilcoxon rank sum test was used to compare the median scores for each parameter in responders and non-responders to zygapophysial joint injections. The results were expressed as the means of the rank sums in each group, with $p$ values. When examining the association between two discrete variables, the Pearson Chi Squared test was used. The Bonferoni method was used to take account of multiple tests. A result was considered significant if $\mathrm{p}$ was less than $0 \cdot 01$.

\section{Results}

In all, 316 injections were performed at 218 levels. Injections were performed bilaterally at 98 segmental levels $(45 \%)$, while 67 injections $(31 \%)$ were right sided and $53(24 \%)$ were left sided. Sixty three patients underwent placebo injections and intra-articular injections were performed at the following levels and at the following frequencies: 57 at L5-S1, 49 at L4-5, 46 at L3-4, two at L2-3 and one at L1-2.

Fifty seven patients completed the study. Five patients failed to proceed to the intraarticular injections and one patient left the study after receiving the first injection. Of the five patients who failed to proceed, four were free of pain for a prolonged period after the placebo injection and therefore did not require further injections, and one developed a generalised skin rash, which was unrelated to any of the procedures. By the time the rash resolved, the patient's pain had largely subsided and therefore blocks of the zygapophysial joints were no longer required. The patient who left the study experienced features of L5 motor and sensory loss after injection of the L5-S1 zygapophysial joint. This was believed to be caused by extracapsular spread of local anaesthetic and the neurological symptoms resolved completely after six hours. The analgesic response could not be assessed and it was recorded as a failed block. The patient subsequently withdrew from the study. No other patient suffered anaesthesia to a spinal nerve.

Twenty of the 63 patients $(32 \% ; 95 \%$ confidence interval (CI) 20 to $44 \%$ ) who underwent placebo injections obtained a greater than $50 \%$ reduction in pain maintained for at least three hours. A diagnosis of zygapophysial joint pain was made in 23 of 57 patients $(40 \%$; 95\% CI 27 to $53 \%)$. When those patients who could not complete the study were included in the analysis a diagnosis of zygapophysial joint pain could be made in $37 \%$ (95\% CI 25 to $49 \%$ ). Eighteen patients obtained $90 \%$ or greater relief of pain; seven of these obtained complete relief of pain. If a positive response to injection is defined as abolition of $90 \%$ of the original pain, the prevalence of zygapophysial joint pain was $32 \%(95 \%$ CI 20 to $44 \%$ ); if a positive response to injection is defined as total abolition of pain, this figure reduces to $12 \%$ ( $95 \%$ CI 3 to $21 \%$ ) of those who completed the study or $11 \%(95 \%$ CI 3 to $19 \%)$ of those admitted to the study.

Eighteen patients obtained relief at only one level. Five other patients obtained relief at more than one level after single injections on separate occasions; three had relief at two levels and two at all three levels. When the joints considered as sources of pain were those in which injection gave the greatest relief for each patient, L5-S1 (eight) and L4-5 (eight) were the most common levels, followed by L3-4 (six) and L2-3 (one).

Assessment of interobserver agreement revealed that measurements of forward flexion were reliable (intraclass correlation coefficients of $0.81-0.94$ for the Schober's test and $0.73-0.93$ using the inclinometric method), but measurements of extension were variably reliable $(0 \cdot 18-0 \cdot 83)$. For lateral flexion, the inclinometric measurements performed slightly better than measurements using the vertical rule. There was greater interobserver agreement for range of lateral flexion than finger to floor distance. Intraclass correlation coefficients ranged from 0.80 to 0.98 for the inclinometric method and from 0.73 to 0.86 when range of movement in centimetres was considered. There was moderate interobserver agreement using the inclinometric method for straight leg raising; intraclass correlation coefficients ranged from 0.63 to 0.86 . For rotation combined with extension, kappa scores ranged from 0.35 to $0 \cdot 80$, indicating fair to substantial agreement. ${ }^{48}$ Intraobserver agreement was best for tests of forward flexion and lateral flexion and least reliable for tests that measured extension.

There was no statistically significant difference in the demographic features, levels of pain and findings on history and physical examination between patients with and without pain originating from the zygapophysial joint (tables 1-4). Levels of anxiety and depression were not significantly different

Table 1 Comparison of demographic features in patients with and without a diagnosis of zygapophysial joint pain

\begin{tabular}{|c|c|c|c|}
\hline Feature & $\begin{array}{l}Z \text { joint } \\
\text { positive }\end{array}$ & $\begin{array}{l}Z \text { joint } \\
\text { negative }\end{array}$ & $p \dagger$ \\
\hline Age (years) & 61 & 59 & 0.84 \\
\hline Duration of low back pain (months) & 132 & 60 & 0.07 \\
\hline $\begin{array}{l}\text { Duration of current episode } \\
\text { of low back pain (months) }\end{array}$ & 9 & $12 \cdot 5$ & 0.81 \\
\hline
\end{tabular}

tDerived from Wilcoxon rank sum test.

$\mathrm{Z}$ joint = zygapophysial joint; median values given. 
Table 2 Level of pain: comparison between patients with and without zygapophysial joint pain

\begin{tabular}{llll}
\hline Feature & $\begin{array}{l}Z \text { joint } \\
\text { positive }\end{array}$ & $\begin{array}{l}Z \text { joint } \\
\text { negative }\end{array}$ & $p \dagger$ \\
\hline VAS (mm) & & & \\
Day pain & 47 & 44.5 & $0 \cdot 47$ \\
Night pain & 22 & $22 \cdot 5$ & 0.98 \\
Pain on movement & 50 & 70 & $0 \cdot 23$ \\
PPI & 2 & 2 & 0.40 \\
PRI (T) & 21 & 21 & $0 \cdot 84$ \\
\hline
\end{tabular}

†Wilcoxon rank sum test.

$Z$ joint = zygapophysial joint; median values

VAS = visual analogue scale; PPI = present pain intensity,

derived from the McGill Pain Questionnaire; PRI (T) = total of

the rank values of the words in the McGill Pain Questionnaire.

Table 3 Comparison of examination features between patients with and without zygapophysial joint pain

\begin{tabular}{lccl}
\hline Feature & $\begin{array}{l}Z \text { joint } \\
\text { positive }\end{array}$ & $\begin{array}{l}\text { Z joint } \\
\text { negative }\end{array}$ & p† \\
\hline Mod. Schober's index (cm) & $5 \cdot 1$ & $5 \cdot 15$ & $0 \cdot 83$ \\
Flexion (deg) & 93 & $84 \cdot 5$ & $0 \cdot 42$ \\
Extension (deg) & 17 & $19 \cdot 5$ & $0 \cdot 47$ \\
Lateral flexion (cm) & & & \\
$\quad$ Left & $15 \cdot 7$ & $14 \cdot 0$ & $0 \cdot 64$ \\
$\quad$ Right & $14 \cdot 7$ & $15 \cdot 5$ & $0 \cdot 64$ \\
SLR right (deg) & 93 & 85 & $0 \cdot 38$ \\
SLR left (deg) & 90 & 84 & $0 \cdot 40$ \\
\hline
\end{tabular}

+Wilcoxon rank sum test. SLR = Straight leg raising; $Z$ joint = zygapophysial joint; median values.

Table 4 Comparison of history and examination features between patients with and without zygapophysial joint pain

\begin{tabular}{ll}
\hline Historical or examination feature & $p \dagger$ \\
\hline Leg pain & $0 \cdot 10$ \\
Dysaesthesia in legs & $0 \cdot 48$ \\
Pain on flexion & $0 \cdot 78$ \\
Pain on extension & $0 \cdot 46$ \\
Pain on right rotation and left extension & $0 \cdot 42$ \\
Pain on left rotation and right extension & $0 \cdot 39$ \\
\hline$t x^{2}$ test. &
\end{tabular}

Table 5 Comparison of scores for the Beck Depression Index (BDI) and the State-Trait Anxiety Index (STAI) in patients with zygapophysial joint pain and patients with other sources of pain

\begin{tabular}{lccc}
\hline Result of psychometric test & $\begin{array}{l}Z \text { joint } \\
\text { positive }\end{array}$ & $\begin{array}{l}Z \text { joint } \\
\text { negative }\end{array}$ & $p \dagger$ \\
\hline BDI & 8 & 8 & $0 \cdot 92$ \\
STAI (state) & 44 & $44 \cdot 5$ & $0 \cdot 88$ \\
STAI (trait) & 46 & $45 \cdot 5$ & $0 \cdot 87$ \\
\hline
\end{tabular}

†Wilcoxon rank sum test.

$\mathrm{Z}$ joint $=$ zygapophysial joint; median values .

between responders and non-responders (table 5).

\section{Discussion}

This study is the first to have assessed the prevalence of zygapophysial joint pain using control injections of normal saline. The study was designed to incorporate a placebo control injection because references had been made in the literature to the possibility of false positive responses. ${ }^{36-38}$ Two other studies have since shown that the false positive rate of uncontrolled injections of the zygapophysial joints can be as high as $38 \%{ }^{50} 51$

Without taking into account the placebo response, the current prevalence of pain of $40 \%$ would be falsely increased to $68 \%$; some $32 \%$ of patients would falsely be given the diagnosis of zygapophysial joint pain. Failure to consider the placebo response may be one reason why several previous estimates of the prevalence of zygapophysial joint pain were so high. ${ }^{1-16}$

The present study addressed the issue of a single zygapophysial joint being the main source of unilateral low back pain or, in the case of bilateral pain, a pair of joints. It expressly did not study the simultaneous contribution of joints from more than one level. It may well be that the prevalence estimate of $40 \%$ for zygapophysial joint pain was an underestimate and, had several levels been injected on one occasion, more patients might have been granted the diagnosis. The contribution of multiple joints could form the subject of future studies. Interestingly, five of the 23 patients with a diagnosis of zygapophysial joint pain experienced a greater than $50 \%$ diminution in pain after the injection of different joints on separate occasions. No adequate explanation can be provided other than the possibility that these patients obtained placebo responses following some injections but did not experience a placebo response on the day of the saline injection. The majority of the 23 patients $(78 \%)$ experienced relief at one level only.

The patients included in this study were those seen by rheumatologists practising at a tertiary referral hospital. The prevalence of $40 \%$ therefore pertains only to such a population and no inferences can be made as to the wider prevalence of zygapophysial joint pain. These figures are greater than those obtained in a recent study of North American patients with chronic low back pain in which the prevalence of zygapophysial joint pain was $15 \% .{ }^{16}$ Such discrepancies may be a result of the very different study populations. For example, in the present Australian study, patients were predominantly female, the median age was 59 years and none was receiving worker's compensation. By contrast, in the American study patients were mainly male, the median age was 38 years and $75 \%$ were receiving such compensation. ${ }^{16}$

One potential criticism of the present study is the problem of referral bias. However, referral bias is not an issue: the present study was designed expressly to study the type of patients seen by rheumatologists. In principle it is possible that, because all the rheumatologists knew the focus of the study, there may have been a tendency to refer patients with zygapophysial joint pain as opposed to patients with other diagnoses. However, as borne out by the present study, the diagnosis of lumbar zygapophysial joint pain cannot be made on history and clinical examination. Therefore, the participating clinicians could not have preferentially referred patients with the proband condition. At best they could have selected only patients with idiopathic low back pain once patients with overt radiculopathy, neurological signs or neoplastic, metabolic or inflammatory disorders had been excluded. It is for that type of patient that the present prevalence figure pertains. 
In conventional practice, recall bias and observer bias can affect the validity of diagnostic decisions. These were eliminated in the present study by requiring every patient to complete a series of VASs for eight hours after each and every injection while undertaking activities that would customarily bring on their pain. The written record circumvented any problem the patient might have had in remembering how much relief they obtained, and provided the observer with an objective measure of the degree of relief and its duration.

The prevalence estimate of $40 \%$ was that obtained when the definition of a positive block was a greater than $50 \%$ relief of pain. This threshold of $50 \%$ was based on an a priori decision made because it was considered that sources other than the zygapophysial joint may also be responsible for pain in these patients. However, $32 \%$ of patients obtained $90 \%$ relief and in these patients other sources of pain would have had an extremely minor role. The $95 \%$ confidence limits of this latter estimate establish that the prevalence of lumbar zygapophysial joint pain would be at least $20 \%$, but could be as high as $44 \%$. When the criterion for zygapophysial joint pain is the complete loss of pain, the proportion diminishes to $12 \%$. This figure is comparable to those from earlier large studies. ${ }^{15} 17$

One limitation of the present study is the possibility that some patients responding to placebo injections may in fact have been patients with true zygapophysial joint pain. A positive placebo response does not exclude real pathology. Thus the true prevalence of lumbar zygapophysial joint pain may, in reality, be greater than indicated in the present study. However, if patients respond to the placebo injection a diagnosis of zygapophysial joint pain cannot be sustained unless further placebo injections are performed. Such a study could not be justified on ethical grounds.

In the present study the null hypothesis that zygapophysial joint pain is an uncommon condition was refuted. A condition with a prevalence even as low as $20 \%$ cannot be considered uncommon. However, the study failed to refute the null hypothesis that there are no clinical features that reliably discriminate between patients with pain of zygapophysial joint origin and pain of other sources. None of the clinical signs tested was found to be a useful discriminator of zygapophysial joint pain. This study confirms the results of Schwarzer et al, ${ }^{16}$ Jackson et al ${ }^{17}$ and Revel et al, ${ }^{28}$ but contradicts the findings of Fairbank et $a l^{4}$ and Helbig and Lee. ${ }^{12}$ The last two studies, however, used single uncontrolled blocks, which is likely to be the basis for the difference in results.

Whereas the results of the present study may be disappointing to those intent on diagnosing lumbar zygapophysial joint pain by clinical examination, ${ }^{4}{ }^{12}$ they do dispute the nihilism directed towards this entity in some quarters. ${ }^{18-21}$ Under stringent, controlled conditions, lumbar zygapophysial joint pain was found to have a substantial prevalence, at least in an Australian population of patients with low back pain. Why some, in other countries, fail to encounter this same prevalence might be explained by differences in their patients, their referral patterns and their selection bias. However, in the face of the results of the present study, failure to diagnose lumbar zygapophysial joint pain in some quarters is not evidence that the condition does not exist.

The present study does not, however, endorse the gratuitous application of the diagnosis. The diagnosis of lumbar zygapophysial joint pain can only, and should only, be made on the basis of controlled diagnostic blocks in each and every patient. Without such measures, false positive responses exaggerate the prevalence of this condition.

Dr Schwarzer was supported by a Scholarship awarded by the New South Wales Department of Health. We wish to thank Dr Michael Jones for his statistical advice.

1 Mooney V, Robertson J. The facet syndrome. Clin Orthop 1976; 115: 149-56.

2 McCall I W, Park W M, O'Brien J P. Induced pain referral from posterior lumbar elements in normal subjects. Spine 1979; 4: 441-6.

3 Carrera G F. Lumbar facet joint injection in low back pain and sciatica: preliminary results. Radiology 1980; 137: $665-7$.

4 Fairbank J C T, Park W M, McCall I W, O'Brien J P. Apophyseal injection of local anesthetic as a diagnostic aid in primary low-back pain syndromes. Spine 1981; 6: 598-605.

5 Destouet J M, Gilula L A, Murphy W A, Monsees B. Lumbar facet joint injection: indication, technique, clinical correlation, and preliminary results. Radiology 1982; 145: 321-5.

6 Carrera G F, Williams A L. Current concepts in evaluation of the lumbar facet joints. Crit Rev Diagn Imaging 1984; 21: 85-104.

7 Raymond J, Dumas J. Intraarticular facet block: diagnostic test or therapeutic procedure? Radiology 1984; 151: 333-6.

8 Lippitt A B. The facet joint and its role in spine pain. Management with facet joint injections. Spine 1984; 9: $746-50$

9 Lau L S, Littlejohn G O, Miller M H. Clinical evaluation of intra-articular injections for lumbar facet joint pain. Med $\mathcal{F}$ A ust 1985; 143: 563-5.

10 Lewinnek G E, Warfield C A. Facet joint degeneration as a cause of low back pain. Clin Orthop 1986; 213: 216-22.

1 Murtagh F R. Computed tomography and fluoroscopy guided anesthesia and steroid injection in facet syndrome. Spine 1988; 13: 686-9.

12 Helbig T, Lee C K. The lumbar facet syndrome. Spine 1988; 13: 61-4.

13 Moran R, O'Connell D, Walsh M G. The diagnostic value of facet joint injections. Spine 1988; 13: 1407-10.

14 Marks R. Distribution of pain provoked from lumbar facet joints and related structures during diagnostic spinal infiltration. Pain 1989; 39: 37-40.

15 Carette S, Marcoux S, Truchon R, et al. A controlled trial of corticosteroid injections into facet joints for chronic low back pain. N Engl f Med 1991; 325: 1002-7.

16 Schwarzer A C, Aprill C N, Derby R, Fortin J, Kine G, Bogduk $N$. Clinical features of patients with pain stemming from the lumbar zygapophysial joints: Is the lumbar facet syndrome a clinical entity? Spine 1994; 19: 1132-7.

17 Jackson R P, Jacobs R R, Montesano P X. Facet joint injection in low-back pain: a prospective statistical study. Spine 1988; 13: 966-71.

18 Jackson R P. The facet syndrome. Myth or reality? Clin Orthop 1992; 279: 110-21.

19 Deyo R A. Fads in the treatment of low back pain. $N$ Engl f Med 1991; 325: 1039-40.

20 Nachemson A L. Newest knowledge of low back pain: a critical look. Clin Orthop 1992; 279: 8-20.

21 Lilius G, Harilainen A, Laasonen E M, Myllynen P. Chronic unilateral low-back pain. Predictors of outcome of facet joint injections. Spine 1990; 15: 780-2.

22 Ghormley R K. Low back pain with special reference to the articular facets, with presentation of an operative procedure. $\mathscr{F} A M A$ 1933; 101: 1773-7.

23 Badgley C E. The articular facets in relation to low-back pain and sciatic radiation. $\mathcal{F}$ Bone foint Surg 1941; 23: 481-96.

24 Bogduk N, Twomey L T. The zygapophysial joints. In: Bogduk N, Twomey L T, eds. Clinical anatomy of the lumbar spine. Melbourne: Churchill Livingstone, 1991; 27-34

25 Bogduk N, Twomey L T. Nerves of the lumbar spine. In: Bogduk N, Twomey L T, eds. Clinical anatomy of the 
lumbar spine. Melbourne: Churchill Livingstone, 1991; 107-20. 26 Bogduk N. The innervation of the lumbar spine. Spine 1983;
8: 286-93.

27 Bogduk N, Wilson A S, Tynan W. The human lumbar dorsal rami. F Anat 1982; 134: 383-97.

28 Revel M E, Listrat V M, Chevalier X J, et al. Facet joint block for low back pain: identifying predictors of a good response. Arch Phys Med Rehabil 1992; 73: 824-8.

29 Bough B, Thakore J, Davies M, Dowling F. Degeneration of the lumbar facet joints. Arthrography and pathology. f Bone foint Surg Br 1990; 72: 275-6.

30 Eisenstein S M, Parry C R. The lumbar facet arthrosis syndrome-clinical presentation and articular surface changes. F Bone foint Surg Br 1987; 69: 3-7.

31 Twomey L T, Taylor J R, Taylor $M$ M. Unsuspected damage to lumbar zygapophyseal (facet) joints after motor-vehicle accidents. Med f Aust 1989; 151: 210-7.

32 Schwarzer A C, Wang S, O'Driscoll D, Harrington T, Bogduk N, Laurent R. The role of computed tomography in predicting the painful zygapophysial joint in patients with chronic low back pain. Spine. In press.

33 Lawrence J S, Bremner J M, Bier F. Osteoarthrosis: prevalence in the population and relationship between prevalence in the population and relationship between $1-23$.

34 Magora A, Schwartz A. Relation between the low back pain syndrome and $\mathrm{X}$-Ray findings. I. Degenerative osteoarthritis. Scand F Rehab Med 1976; 8: 115-25.

35 Wiesel S W, Tsourmas N, Feffer H L, et al. A study of computer-assisted tomography: I. The incidence of positive CAT scans in an asymptomatic group of patients. Spine 1984; 9: 549-51.

36 Boas R A, Cousins M J. Diagnostic neural blockade. In: Cousins M J, Bridenbaugh P O, eds. Neural blockade in clinical anaesthesia and management of pain. Philadelphia: J B Lippincott Company, 1988; 885-98.

37 Boas R A. Nerve blocks in the diagnosis of low back pain Neurosurg Clin N Am 1991; 2: 807-16.

38 Melzack R. Psychological aspects of pain: implications for neural blockade. In: Cousins M J, Bridenbaugh P O, eds.
Neural blockade in clinical anaesthesia and management of pain. Philadelphia: J B Lippincott Company, 1988; 845-60.

39 Quebec Task Force on spinal disorders: Chairman Spitzer WO. Scientific approach to the assessment and management of activity-related spinal disorders: monograph for clinicians; report of the Quebec Task Force on spinal disorders. Spine 1987; 12: S1-59.

40 Deyo $R$ A Practice variations, treatment fads, rising disability: do we need a new clinical research paradigm? Spine 1993; 18: 2153-62.

41 Melzack R. The McGill Pain Questionnaire: major properties and scoring methods. Pain 1975; 1: 277-99.

42 Spielberger C D, Gorsuch R L, Lushene R, Vagg P R Jacobs G A. Manual for the State-Trait Anxiety Inventory (Form Y). Palo Alto: Consulting Psychologists Press, Inc., 1983; 1-35.

43 Beck A T, Steer R A, Garbin M G. Psychometric properties of the Beck Depression Inventory: twenty-five years of evaluation. Clin Psychol Rev 1988; 8: 77-100.

44 Peck C, Coleman G. Implications of placebo theory for clinical research and practice in pain management. Theor Med 1991; 12: 247-70.

45 SPSS Inc. SPSS Data Entry II. Chicago: SPSS Inc., 1987.

46 Brown M B, Engelman L, Jennrich R I. BMDP Statistical Software, Volumes $1 \& 2$. Berkley: University of California Press, 1990.

47 SAS Institute Inc. SAS/STAT User's Guide, Version 6, Volume 2. Cary, NC: SAS Institute Inc., 1989

48 Seigel D G, Podgor M J, Remaley N A. Acceptable value of kappa for comparison of two groups. Am 7 Epidemio 1992; 135: 571-8

49 Morton A P, Dobson A J. Assessing agreement. Med f Aust 1989; 150: 384-7.

50 Barnsley L, Lord S, Wallis B, Bogduk N. False-positive rate of cervical zygapophysial joint blocks. Clin f Pain 1993; 9: $124-30$.

51 Schwarzer A C, Aprill C N, Derby R, Fortin J, Kine G Bogduk $\mathrm{N}$. The false-positive rate of uncontrolled diagnostic blocks of the lumbar zygapophysial joints. Pain 1994; 58: 195-200. 